\title{
TR5 (Batı Anadolu) Bölgesinin İnovasyon Performans Kapasitesi Üzerine Bir Uygulama ${ }^{1}$
}

Zeynep KARAÇOR ${ }^{2}$, Erhan DUMAN ${ }^{3}$

TR5 (West Anatolia) Region With an Application on the Performance of Innovation Capacity

\begin{tabular}{l} 
ARTICLE INFO \\
\hline Article History: \\
Date Submitted: 27.04 .2017 \\
Date Accepted: 04.05.2017 \\
\hline JEL Classification: \\
O3 \\
O4 \\
R3
\end{tabular}

Keywords:

Regional Innovation

Systems

Economic Growth

MATLAB

Regional Innovation Index and the Measurement

\begin{abstract}
Economic decision units are need in order to raise competitiveness and economic growth to provide resource to develop social welfare in the age of knowledge economy. The economic structure in these resources are emerging innovation. Therefore, the new world economy as a production factor is important where innovation of analyzing the relationship between economic growth. In this study, the relationship between regional innovation and economic growth are investigated by MATLAB program normalization methods. In this context, the innovation performance and capacity of the regions aim to develop within the scope of the level 1 metrics that allow comparison of the average regions in Turkey. Among the variables to determine the normality was performed by Kolmogorov-Smirnov statistical fit test. Also the z-score normalization method that should be applied information is presented about the regions innovation policies of determined the levels.
\end{abstract}

\footnotetext{
${ }^{1}$ Bu çalışmama Selçuk Üniversitesi Prof Dr. Zeynep KARAÇOR danışmanlığında Erhan DUMAN'ın “Bölgesel İnovasyon ve İktisadi Büyüme: Düzey 1 Kapsamındaki Bölgelerin Normalizasyon Yöntemiyle Analizi” başlıklı doktora tezinden türetilmiştir.

${ }^{2}$ Prof.Dr. Selçuk Üniversitesi, İktisadi İdari Bilimler Fakültesi, zkaraçor@selcuk.edu.tr

${ }^{3}$ Öğr.Gör. Dr. Bitlis Eren Üniversitesi, Ahlat Meslek Yüksek Okulu, eduman@beu.edu.tr
} 


\section{Özet}

Ekonomik karar birimleri bilgi ekonomisi çağında toplumsal refahı ve rekabeti yükseltebilmek için iktisadi büyümeyi sağlayacak olan kaynaklara ihtiyaç duymaktadırlar. Bu durum dinamik ekonomi içerisinde inovasyonla ortaya çıkmaktadır. Bu nedenle inovasyonun bir üretim faktörü gibi karşımıza çıktığı yenidünya ekonomisinde ekonomik büyüme ile arasındaki ilişkinin analiz edilmesi önem arz etmektedir. Bu çalışmada bölgesel inovasyon ile iktisadi büyüme arasındaki ilişki Matlab programı yardımıyla normalizasyon yöntemleriyle incelenmektedir. Bu çerçevede, Türkiye'de Düzey 1 kapsamındaki TR5 bölgesinin inovasyon performans kapasitesinin ve sınıfının belirlenmesi amaçlanmaktadır. Değişkenler arasında normalliği tespit etmek için Kolmogorov-Smirnov istatistik uyum testi gerçekleştirilmiştir. Ayrıca Z Skor Normalizasyon yöntemiyle bölgelerin inovasyon sınıfları belirlenmiş ve uygulanması gereken politikalar hakkında bilgiler sunulmuştur.

Anahtar Kelimeler: Bölgesel İnovasyon Sistemleri, Ekonomik Büyüme, MATLAB, Bölgesel İnovasyon Endeksi ve Ölçümü.

\section{Giriş}

İnovasyon olgusu dünyayı her geçen gün değiştirmeye devam etmektedir. Bu süreçte ortaya çıkan ekonomik birimler, politik çevreler, sosyal ve kültürel değerler gelişen sistemin birer parçası olmaktadırlar. Bu kapsamda, teknolojideki yeniliklere ayak uydurmanın veya yenilikleri yakalamanın güçleştiği ve bilginin hayati önem taşıdığg günümüz dünyasında, ekonomiler büyümenin ayrılmaz bir parçası olarak inovasyonu öne çıkarmaktadırlar. $\mathrm{Bu}$ çerçevede iktisadi büyümeyi hedefleyen bölgelerin hemfikir olduğu nokta; inovasyon politikalarına yönelik bilimsel ve teknolojik ilerlemeleri yakından takip etmenin yanı sıra bu politikalar için gerekli olan altyapıyı oluşturmaktır.

Günümüzde ekonomik karar birimlerinin davranışlarını şekillendiren unsurların başında gelen inovasyon, modern iktisat teorilerinin ilgi odağı haline gelmiştir. Dolayısıyla ekonomik sistem içerisinde üretimdeki değişiklikler her yaklaşıma göre farklılık arz etmektedir. Örneğin, klasik iktisatçılar teknolojik gelişme ile ekonomik büyüme arasındaki ilişkiyi çok fazla incelememişlerdir. Neoklasik iktisatçılar ise ekonomik büyüme ile teknolojik 
değişim ve nüfus artışı arasındaki ilişkiyi ortaya koymaya çalışmışlardır. Fakat modellerinde teknolojik değişmeyi dişsal olarak değerlendirmişlerdir. Schumpeter, ekonomik büyüme kapsamında inovasyonun zorunlu olduğunu belirtmiştir. İçsel ekonomik büyüme modellerinde ise teknolojik değişme ve gelişmeler ile ekonomik büyüme arasındaki ilişki ele alınmıştır. Böylece teknolojik değişme ekonomik büyüme modellerine içsel bir değişken olarak dâhil edilmiştir.

Ülkeler ve firmalar bölgeselleşme olgusunun da etkisiyle bilimsel ve teknolojik gelişmenin hızlanması, artan rekabet, enformasyon gibi bileşenlerden ötürü inovasyon faaliyetlerine daha fazla ihtiyaç duymaktadırlar. $\mathrm{Bu}$ faaliyetler temelde; ülke içerisinde üretilen bilgi ve teknolojilerin ticarileştirilmesi, işgücü verimliliğinin artırılması, fikri mülkiyet haklarının korunması ve sosyal-fiziksel-beşeri sermaye seviyesinin yükseltilmesiyle ekonomik büyümeye dayanmaktadır. Bu doğrultuda, literatürdeki inovasyon ile ilgili ampirik ve teorik çalışmalar ekonomik büyüme aşamasında inovasyonun önemli bir unsur olduğunu göstermektedir. Çalışmanın amacı doğrultusunda Z Skor Normalizasyon yöntemiyle bölgelerin inovasyon sınıfları belirlenmiş ve uygulanması gereken politikalar hakkında bilgiler sunulmuştur. Ayrıca değişkenler arasında normalliği tespit etmek için KolmogorovSmirnov istatistik uyum testi gerçekleştirilmiştir.

\section{Bölgesel İnovasyon Sistemi ve Ekonomik Büyüme}

Bölgeler arasında artan rekabetle birlikte bölgesel inovasyon sistemi ekonomik büyüme üzerinde giderek önemi artan bir konuma gelmektedir. Bölgesel inovasyon sistemin ekonomik büyüme açısından önem arz etmesinin iki temel nedeni vardır: İlk olarak, ulusal inovasyon politikası amaçlarına ulaşmak için bölgelerde üretilen güçlü inovasyon dinamikleri açısından önemlidir. İkinci olarak da piyasa aktörlerinin verimliliğine katkı sağlayan inovasyon performansı aynı zamanda bölgelerin rekabet gücünü arttırmaktadır (OECD, 2008:49). Bölgesel inovasyon sisteminin iktisadi büyüme üzerinde önem kazanmasına yol açan diğer faktörler; iş gücünün niteliği ve yeterliliği, bölgenin sahip olduğu nitelikli nüfusu, eğitim-araştırma kuruluşlarının kalitesi, altyapı yeterliliği, girişimcilik kültürü, bilgi birikimi ve bilginin dağılımının bölgeler arasında farklı yapıda olması şeklindedir. Ayrıca üretim sürecinde birbirine bağımlı bilgi üreten kuruluşlardan ve müşterilerden oluşan sanayi 
işbirlikleri genellikle bölgesel alt yapıları ile özgün inovasyon sistemlerini oluşturmaktadır. Bölgesel inovasyon sisteminde koordineyi sağlayan aktörlerin etkileşimi, bilgi dışsallıkları, ortaya çıkan ürün ve hizmetlerin yerel özellik taşıması bu sistemi ekonomik büyüme açısından önemli kılmaktadır (Durgut ve Akyoş, 2001:7-8).

Bölgesel olarak ekonomik büyümeye yönelik yapılan araştırmaların temelinde iki özellik mevcuttur: Bu özelliklerden birincisi; bölgesel inovasyon ekonomik, sosyal, politik ve kurumsal olarak meydana gelmektedir. Bu kapsamda, ekonomik etkileşim ve inovasyon açısından bölgeler verimli alanlar olarak ele alınmaktadır. İkinci olarak; bölgesel inovasyon coğrafi yakınlık ve teknolojik yoğunlaşma olduğu sürece meydana gelmektedir (Doloreux, 2002:245). Bu süreçte bölgesel aktörler merkezi rol üstlenmektedir. Bölgesel inovasyon politikaları ve ekonomik büyüme, aktörler arasındaki işbirliği sayesinde olumlu yönde etkilenmektedir.

Bölgesel inovasyon politikaları uygulanırken bir takım farklı etkiler ortaya çıkmaktadır. Bölgelerin ekonomik büyümeye katkıları üretimin mekâna bağlılığı ile alakalıdır. Bu durumu bölgesel yan etkiler ile açıklamak mümkündür. Uygulanan politikalar bölgesel olmasa bile etkileri bakımından bölgesel özellik taşıyabilir. Bölgeler arası serbestleşme, mal, hizmet ve sermaye akımlarının hızlanması bölgesel aktörlerin büyük hacimli piyasalar etrafında yoğunlaşmasına neden olmaktadır. Bu etkiyi de bölgesel entegrasyon olarak tanımlamak mümkündür. Ayrıca bir bölgede özellikle üretim faktörlerinin hareketliliği kısıtlı ise uygulanan inovasyon politikalarında istenilen verim alınamaz. $\mathrm{Bu}$ etkiye eşik etkisi denir. Bir diğer etki kitlenme etkisidir. Bu etki bölgede ekonomik büyüme gerçekleşmeye başladıktan sonra bölge içerisinde farkların artması durumudur. Politikalar sonucunda ortaya çıkan bu etkiler, bölgelerde ekonomik büyümenin gerçekleşebilmesi için üretim faktörleri hareketliliğinin serbest olmasına ve inovasyon üzerine odaklanmaktadırlar. Ayrıca bölgesel inovasyon politikalarının geliştirilmesiyle beraber üretim ve istihdam oranlarındaki artışlar ekonomik büyümeye katkı sağlamaktadır (TÜSİAD, 2008: 35-36).

Bölgesel inovasyon politikalarını önemli kılan bir diğer unsurda bölgeselleşme, kurumsal altyapı ve ekonomik büyüme arasındaki pozitif ilişkidir. Bu pozitif yönlü ilişkinin oluşabilmesi için; teknolojik ürünün üretilmesi, pazarlanması, organize edilerek farklı 
şekillerde sunulması ve ticarileşmesi gerekmektedir. $\mathrm{Bu}$ doğrultuda, üniversite-sanayi işbirlikleri, ar-ge enstitüleri, teknopark-teknokentler, kalkınma ajansları ve araştırma merkezleri gibi kurum-kuruluşlar ekonomik büyüme sürecinde hem ulusal hem de bölgesel anlamda önemli rol oynamaktadırlar. Bölgelerin istikrarlı bir iktisadi büyümeye sahip olabilmesi için etkin bir inovasyon sistemiyle teknik açıdan ileri seviyede teknolojileri üretmesi ve kullanması gerekmektedir. Bu nedenle, teknolojik faaliyetlerin yoğunluğu, ar-ge harcamaları teşvikleri, girişimciliği destekleme açısından görev üstlenen kurumların finansmana erişim kolaylığı gibi faktörler bölgelerin gelişmişliği anlamında oldukça önemlidir (Niosi, 2008:616). Bu doğrultuda literatürdeki inovasyon ile ilgili çalışmalar, iktisadi büyüme aşamasında bölgesel inovasyonun önemli bir unsur olduğunu göstermektedir.

Bölgesel inovasyon sistemi 1950'li yıllarda uygulamaya girmiş olsa da kapsam ve araçlar bakımından büyük değişimler göstermiştir. Örneğin 1960 ve 1970'li yıllarda planlama yönteminin olduğu dönemdir. $\mathrm{Bu}$ dönemde bölgelerin sahip oldukları karşılaştırmalı üstünlükler ve faktörler esas alınmaktadır. 1980'li yıllar stratejik planlama ve rekabetçi üstünlük anlayışı ile bölgesel anlamda yeni bir politika dönemi olmuştur. 1990'lı y1llardaki politikalar tüm bölgelerin hedef alındığı sürdürülebilirlik ve işbirliğinin olduğu bir dönem haline gelmiştir. 2000'li yıllarda ise bu sistem inovasyon süreçlerinin açıklanmasında kullanılan bir yaklaşım olmuştur (Sternberg ve Müller, 2005:1-2).

Bölgesel inovasyon sistemi; piyasa aktörlerinin koordineli olarak bölgesel bütünleşmeyi oluşturduğu ve etkileşimli bir öğrenmeyle dâhil oldukları bir yapıdır. Ayrıca bu sistem sürekli değişimi ve öğrenmeyi destekleyen ekonomik, sosyal, politik, kültürel bir bütününün yapı taşlarını oluşturmaktadır. Bu yapıda bölgesel seviyede gerçekleşen inovasyon işbirlikleri önemlidir. Bölgesel inovasyon sistemi; eğitim kurumları, firmalar, araştırma merkezleri, finansman kuruluşları ve sivil toplum örgütleri gibi çeşitli değişkenler arasında etkileşimin olduğu ortamdır (Cappellin ve Wink, 2009:107). Değişkenler arasındaki etkileşim gerek bölgesel inovasyon gerekse de ekonomik büyüme açısından önem taşımaktadır.

Bölgesel inovasyon sistemi, üretim süreçlerinde inovasyonu destekleyen altyapı olarak değerlendirilmektedir. Bölgesel olarak ekonomik koordinasyon ve büyümenin sağlanabilmesi için sistem içindeki inovasyon bileşenlerinin iletişim kanallarıyla araştırma merkezlerine 
bağlanması gerekmektedir. Ayrıca sistem; bölgeler arası dengesizlikleri en aza indirmek, inovasyona dayalı firmaları ve nitelikli işgücünü bölgeye çekmek, bölgenin rekabet gücünü artırmak için uygulanan politikalar şeklinde ifade edilmektedir. Bu politikalar dâhilinde bölge ekonomisinde uzun vadeli bir büyümeden bahsedilmektedir. Ayrıca bu sisteminin ekonomik verimliliği kurumlar arasındaki işbirliğine bağlıdır. Bölgesel olarak inovasyonu teşvik eden kurumsal altyapı o bölgedeki üretim çeşitliliğine dolayısıyla sektör farklılığına neden olmaktadır. $\mathrm{Bu}$ sistem ekonomik koordinasyonun bölgelerdeki önemli bir dayanağını oluşturmaktadır (Asheim ve Gertler, 2005:299-300).

Bölgesel inovasyon sistemi ekonomik alanlarda sanayi bölgelerinden yenilikçi bir yaklaşımla ulusal inovasyon sistemine kadar olan süreci kapsamaktadır. Bu kapsamda bahsedilen bu iki inovasyon sistemi, belli bir süreç boyunca işbirliği gerektirmektedir. $\mathrm{Bu}$ işbirliği karmaşık ve etkileşimli modellerden oluşmaktadır. Dolayısıyla bu modeller içerisindeki bölgesel inovasyon sistemi ekonomik büyümeyi ortaya çıkaran bir değişkendir (Sternberg, 2007:653).

Cooke, Roper ve Wylie' e göre bölgesel inovasyon sistemi; teknolojik yeniliğin ortaya çıkarılması, yayılımı ve kullanımıyla ilgili olan aktörler arasındaki ilişkilerin oluşturduğu karmaşık bir yapıdır. Aktörlerin koordineli olarak bölgesel düzeyde yeniliğin gelişmesine ve artırılmasına nasıl katkıda bulunduklarını açıklamaktadır. Bu tanıma göre sistem; yerel ve bölgesel kurumlar, firmalar, risk sermaye şirketleri, araştırma ve teknoloji enstitülerinden meydana gelmektedir. Bu aktörlerin etkileşimi sonucunda bilginin piyasada rekabetçi üstünlüğe dönüştürülmesi gerekmektedir (Cooke, Roper ve Wylie, 2001:3).

Bölgesel inovasyon sistemi, inovasyon faaliyetlerinin coğrafi olarak sınırlı olan bir olgudan gelişen deneysel tabanlı bir bilgi sistemine dönüşümüdür. $\mathrm{Bu}$ sistemin temel sorunlar1; aktörlerin inovasyon kapasitelerini bölgesel ölçeğe uyarlama ve bölgesel kaynakların keşfi şeklinde sıralamak mümkündür. Sistemin temel sorunlarına karşın, mekânsal yakınlık bilgi akışını kolaylaştırır ve böylece etkileşimli öğrenmeye katkı sağlar (Canter ve Meder, 2009:13). Bu kapsamda sistem teorik olarak etkileşimli öğrenmeye dayanır. Etkileşimli öğrenmenin temeli bilgi çeşitliliğine ve farklı bilgi donanımına sahip kurumların iletişimine bağlıdır. Koordineli olarak hareket eden kurumlar etkileşimli 
öğrenmeyi teşvik etmektedirler. Bütün bu gelişmeler kurumlar arasındaki iletişim ve işbirliğini artırarak istikrarlı bir ekonomik büyümeye katkı sağlamaktadırlar (Gregersen ve Johnson, 1996:6).

$\mathrm{Bu}$ sistem, yeniliğin desteklenmesi yoluyla bölgedeki firmaların rekabet edilebilir seviyeye gelmelerine katkı sağlamaktadır. Bu kapsamda inovasyon sistemi; bölgelerde yeniliğin artırılmasına yönelik politikaların oluşturulması, bölgenin sahip olduğu kaynakların en etkin şekilde kullanılması ve geliştirilmesi için önem arz etmektedir. Bölgesel inovasyon sisteminin etkin bir şekilde çalışması için bazı temel aşamaları takip etmesi gerekmektedir. $\mathrm{Bu}$ temel aşamalar aşağıdaki gibi sıralamak mümkündür (Elçi vd, 2008: 53-55):

$\checkmark \quad$ Ekonomik karar birimleri arasında bölgesel koordinasyonun oluşturulması,

$\checkmark \quad$ Bölgede bilgi üreticisi konumundaki kurumların varlığı, kalitesi ve yoğunluğu,

$\checkmark \quad$ Bölgedeki firmalar tarafından üretilen bilgiyi veya teknolojiyi kullanma kapasitesi ve nitelikli emek sayısı,

$\checkmark \quad$ Bölgesel kurum ve kuruluşların tamamının inovasyon politikası oluşturulma sürecinde doğrudan katılımının sağlanması,

$\checkmark \quad$ Bölgelerin güçlü, zayıf, tehdit ve fırsat özelliklerinin analizi yapılarak inovasyon için önceliklerin belirlenmesi,

$\checkmark \quad$ Bölgede inovasyonun bir kültür haline gelme zorunluluğu şeklindedir.

$\mathrm{Bu}$ bağlamda bölgeler arasındaki farklılıklar hem ekonomistlerin hem de politikacıların odak noktası olmuştur. Söz konusu bu ilginin temeli ekonomik refah ile bölgesel büyüme arasındaki ilişkiden kaynaklanmaktadır. Bu kapsamda bölgesel inovasyon ile ekonomik büyüme arasındaki ilişki dinamik bir kavram olarak karşımıza çıkmaktadır. Bu dinamik yapının, bilgi ve teknoloji transferlerinde gerek bölge içi gerekse bölgeler arası ilişkilere katkı sağladığını söylemek mümkündür.

\section{Bölgesel İnovasyon Endeks Değişkenleri ve Yöntem}

Bölgesel inovasyon endekslerin oluşturulmasında $\mathrm{AB}$ ile uyum içinde verilerin geliştirilmesinde NUTS göstergeleri incelenmiş ve literatürde ele alınan bazı değişkenler bulunmaktadır. İnovasyon girdileri ve çıktıları altında incelenen bu değişkenler; beşeri, 
ekonomik, sosyal ve yapısal değişkenlerden meydana gelmektedir. Bu bağlamda bölgesel inovasyon ve ekonomik büyüme etki eden temel girdi değişkenleri; mümkün kılıcılar, altyap1kültür ve girişimcilik-ticaret oluşmaktadır. Temel girdi değişkenleri oluşturan alt değişkenler ise; insan kaynakları, araştırma sistemleri, yatırım-kredi-destekler, nüfus, enerji, bilgi iletişim teknolojileri, sağlık, ulaştırma, kültür, girişimcilik, ticaret ve mali aracı kuruluşlardan meydana gelmektedir (Duman, 2017:98-99). Ayrıca bu alt değişkenler 48 bileşenden oluşmaktadır.

Temel çıktı değişkeni ise inovasyon çıktıları altında toplanmıştır. Temel inovasyon çıktıları da yenilikler, bilimsel çıktılar, ekonomik çıktılar ve toplumsal refah olmak üzere dört alt değişken şeklinde sıralanmaktadır (Duman, 2017:100). Bu alt çıktılar da 20 bileşenden meydana gelmektedir.

Endeks değişkenlerin oluşturulmasında bileșenlere ait olan bilgiler en son erişilebilir yıl esas alınarak bir araya getirilmiştir. Bu çerçevede toplanan bilgiler 2009-2016 yılları arasındaki dönemi kapsamaktadır. Toplanan bu veriler temel olarak; Türkiye İstatistik Kurumu (TÜIKK), Bakanlıklar, Uluslararası Öğrenci Değerlendirme Programı (PISA), Yüksek Öğretim Kurumu (YÖK), Türkiye Bankalar Birliği (TBB), Türk Patent Enstitüsü (TPE) ve University Ranking by Academic Performance (URAP) gibi farklı kurum ve kuruluşların yayınladıkları rapor, bülten ve veri tabanlarından alınmıştır.

\section{Normalizasyon Yöntemi}

Bölgesel inovasyon endekslerin oluşturulmasında Avrupa inovasyon skorboard ve bölgesel inovasyon ölçüm yöntemi olan normalizasyon yöntemi kullanılmıştır. Bölgesel inovasyon endekslerinin oluşturulmasına etki eden faktörler ve bu faktörlerin bölgeler üzerindeki etkileri incelenmiştir. Bu bağlamda bölgelere etki eden faktörler normalizasyon yöntemi olan z-skor ile analiz edilmiştir. Ayrıca bölgelerin birbirleriyle karşılaştırılabilmesi için bu yöntem tercih edilmiştir. Z-skor normalizasyon yöntemine göre bileşenler -1 ve +1 puan aralığında yer almaktadır. Ayrıca z-skor normalizasyon yönteminde endeks değerlerine göre bölgeler; üst, orta üst, orta ve alt düzey olarak nitelendirilmektedir (Aydın, 2012:4-22). 
Çalışmanın devamında z-skor yöntemiyle bölgenin inovasyon sınıflaması gerçekleştirilebilmesi ve değişkenlerin normal dağılıma uygun olup-olmadığının belirlenmesi için Kolmogorov-Smirnov test uygulaması yapılmıştır.

\section{Kolmogorov-Smirnov Test Uygulaması}

Elde edilen verilerin, değişkenlerin ve bileşenlerin $\mathrm{z}$ skor değerlerinin normal bir dağılım gösterip göstermediğini test etmek için Matlab programında Kolmogorov-Smirnov uyum testi kullanılmaktadır. Bu test için hipotezler aşağıdaki gibidir.

$\mathrm{H}_{0}$ : Değişkenler normal dağılımlıdır.

$\mathrm{H}_{1}$ : Değişkenler normal dağılımlı değildir.

$\mathrm{Bu}$ testin dışında istatiksel olarak normal dağglıma uyumla ilgili Jarque-Bera ve Lilliefors testleri bulunmaktadır. Ancak bu testler genellikle zaman serilerinde ve sabit z skor değerlerine sahip değişkenleri karşılaştırmak için kullanılmaktadır (Kocakoç, 2015:112).

Kolmogorov-Smirnov testi, değişkenlerin kümülatif değerlerinin $\mathrm{z}$ skor normal dağılımı için standartlaştııılmasını kapsamaktadır. Bu değişkenleri belirlemenin bir diğer yöntemi ise log-normal olabilirlik yöntemidir. Ancak log-normal olabilirlik yönteminde belirlenen değerler dağılımlar arasında en iyi uyumu vermekle beraber değerlerin belirtilen dağılımdan gelme konusunda bir garanti söz konusu değildir. Bu nedenle çalışmada Kolmogorov-Smirnov test tekniği tercih edilmiştir. Bu testin sonuçların yorumlanması için kullanılacak fonksiyon aşağıdaki gibidir. Bu fonksiyon kullanılarak değişkenlerin normal dağılım parametrelerinden gelip gelmedikleri belirlemektedir.

$[\mathrm{H}, \quad \mathrm{P}, \quad \mathrm{KSSTAT}, \mathrm{CV}]=\operatorname{ksstat}($ değişkenin $\mathrm{z}$ skor değerlerinin ortalaması (ans))

$H(\alpha)$ : Değişkenin bölgeler üzerinde önem seviyesinin test sonucudur. Sonuç 0 ise $\mathrm{H}_{0}$ kabul, 1 ise $\mathrm{H}_{0}$ reddedilir ve $\mathrm{H}_{1}$ kabul edilir.

$\mathrm{P}$ : Testin $\mathrm{p}$ anlamlılık değeridir. $\mathrm{P}>\alpha$ ise, $\mathrm{H}_{0}$ kabul edilir. 
KSSTAT: Kolmogorov-Smirnov test istatistiği

CV. Testin kritik değerini göstermektedir. CV > KSSTAT ise $\mathrm{H}_{0}$ kabul edilir (Kocakoç, 2015:128).

Tablo 1:TR5 Bölgesine Ait Değişkenlerin KSSTAT Test İstatistiği Sonuçları

\begin{tabular}{|ll|llll|}
\hline Alt Değişkenler & $\mathbf{H}(\boldsymbol{\alpha})$ & $\mathbf{P}$ & KSSTAT & CV & SONUÇ \\
\hline İnsan Kaynakları & 0 & 0.5335 & 0.2056 & 0.3754 & $\mathrm{H}_{0}$ kabul \\
\hline Araştırma Sistemleri & 0 & 0.4751 & 0.2143 & 0.3754 & $\mathrm{H}_{0}$ kabul \\
\hline Yatırım-Kredi-Destekler & 0 & 0.4043 & 0.2358 & 0.3754 & $\mathrm{H}_{0}$ kabul \\
\hline Nüfus & 0 & 0.5684 & 0.1154 & 0.3754 & $\mathrm{H}_{0}$ kabul \\
\hline Enerji & 0 & 0.5530 & 0.1752 & 0.3754 & $\mathrm{H}_{0}$ kabul \\
\hline Bilgi İletişim Teknolojileri & 0 & 0.6859 & 0.1325 & 0.3754 & $\mathrm{H}_{0}$ kabul \\
\hline Sağlık & 0 & 0.1624 & 0.3245 & 0.3754 & $\mathrm{H}_{0}$ kabul \\
\hline Ulaştırma & 0 & 0.2674 & 0.2875 & 0.3754 & $\mathrm{H}_{0}$ kabul \\
\hline Kültür & 0 & 0.1756 & 0.2698 & 0.3754 & $\mathrm{H}_{0}$ kabul \\
\hline Girişimcilik & 0 & 0.4867 & 0.2214 & 0.3754 & $\mathrm{H}_{0}$ kabul \\
\hline Ticaret ve Mali Kuruluşlar & 0 & 0.1914 & 0.2702 & 0.3754 & $\mathrm{H}_{0}$ kabul \\
\hline Yenilikler & 0 & 0.2982 & 0.2352 & 0.3754 & $\mathrm{H}_{0}$ kabul \\
\hline Ekonomik Çıktılar & 0 & 0.1593 & 0.2245 & 0.3754 & $\mathrm{H}_{0}$ kabul \\
\hline Bilimsel Çıktılar & 0 & 0.3438 & 0.2102 & 0.3754 & $\mathrm{H}_{0}$ kabul \\
\hline Toplumsal Refah & 0 & 0.3790 & 0.1012 & 0.3754 & $\mathrm{H}_{0}$ kabul \\
\hline
\end{tabular}

Tablodaki test sonuçlarında görüldüğü gibi, değişkenlere ait veriler normal dağılıma uygundur. Tabloda $\mathrm{H}$ değerinin $0, \mathrm{P}>\alpha$ ve $\mathrm{CV}>\mathrm{KSSTAT}$ olduğu için $\mathrm{H}_{0}$ hipotezi kabul edilmiştir. Sonuçta ele alınan 15 değişkenin tamamı istatiksel olarak anlamlı çıkmıştır. Bu sonuçlar doğrultusunda değişkenler z skor normalizasyon yöntemiyle analiz edilecektir.

\section{TR5 Bölgesinde Z Skor Yönteminin Uygulanması ve Bulgular}

Z-skor normalizasyon yönteminin fonksiyonu;

$$
\text { Endeks }_{x i}=\frac{x_{i}-\mu}{\sqrt{\frac{1}{n} \sum_{i=1}^{n}\left(x_{i}-\mu\right)^{2}}}
$$

Fonksiyonda; 
xi; endeks değeri hesaplanacak bölgelerin grup içindeki sayısal değerini,

$\boldsymbol{\mu}$; her bir grupta yer alan ortalama değeri ve

$$
\sqrt{\frac{1}{n} \sum_{i=1}^{n}\left(x_{i}-\mu\right)^{2}} \text { ise her bir grupta yer alan standart sapma değerini }
$$

göstermektedir. Fonksiyondan da anlaşılacağı üzere z-skoru tanımlayan parametreler ortalama ve standart sapmadır. Bölgenin endeks değerleri; bölgeye ait grup değeri ile gruptaki ortalama değer farkının, gruptaki standart sapma değerine bölünmesiyle ortaya çıkmaktadır. Bu kapsamda değişkenler arasında inovasyon performansı yüksek olan bölge 0.50 ve 0.50 'den yüksek değerler alırken, inovasyon performansı düşük olan bölge ise 0 ve -1'e yakın değerler almaktadır. Bölgenin sınıflaması -1 ve 0 arası alt, 0 ve 0.25 arası orta, 0.25 ve 0.5 arası ortaüst ve 0.5 yukarısı üst düzey olarak tanımlamaktadır (Annoni ve Kozovska, 2010:56).

Çalışmanın devamında alt değişkenlerin z-skor değerleri grafik olarak verilmektedir. Alt değişkenler numaralandırılmıştır (Kocakoç, 2015: 47). Her numara ayrı bir alt değişkeni göstermektedir. Numaralar sırasıyla; 1) İnsan kaynakları, 2) Araştırma sistemlerini, 3) Yatırım, kredi ve destekleri, 4) Nüfus, 5) Enerji, 6) Bilgi iletişim teknolojileri, 7) Sağlık, 8) Ulaştırma, 9) Kültür, 10) Girişimcilik, 11) Ticaret ve mali aracı kuruluşlar, 12) Yenilikler, 13) Ekonomik çıktılar, 14) Bilimsel çıktılar, 15) Toplumsal refah değişkenini temsil etmektedir.

\section{Şekil 1:TR5 Z-Skor Değerleri}

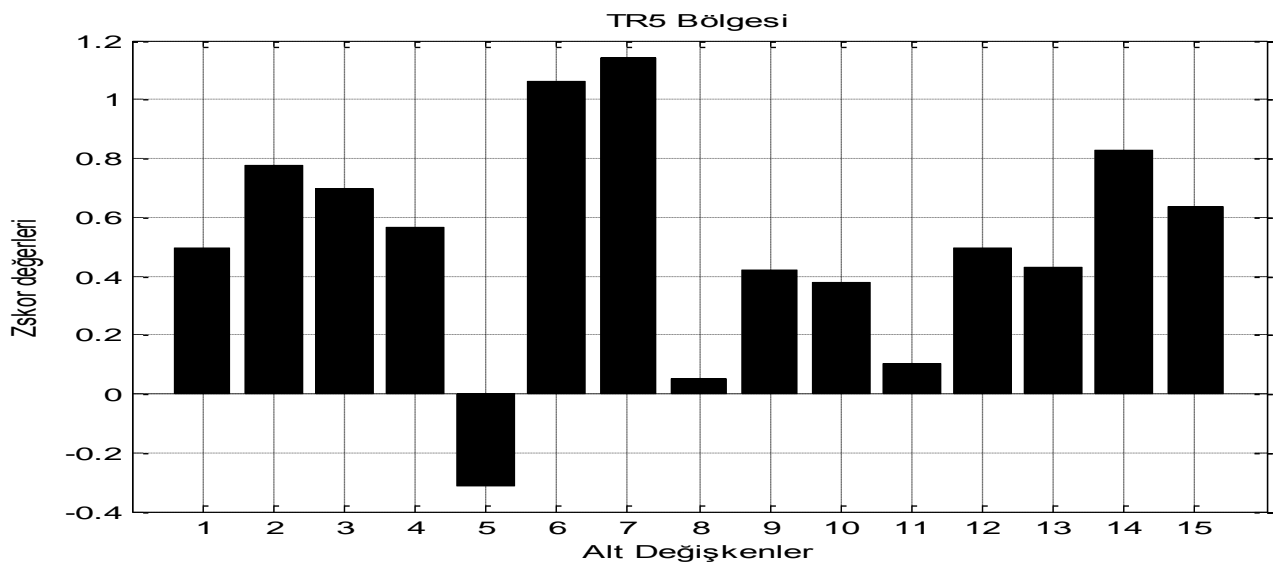


TR5 bölgesi Ankara, Konya ve Karaman illerinden meydana gelmektedir. Şekle göre, Batı Anadolu Bölgesi z-skor alt değişken değerlerinden sadece bir tanesinde negatiftir. Enerji değişkeninin negatif olmasındaki temel etkenler; kişi başına elektrik tüketimi ve kişi başına yeşil enerji üretim bileşenlerinin eksi olmasından kaynaklanmaktadır. Bölge inovasyon kategorisinde üst sınıfta yer almaktadır. Bu durum TR5 bölgesinde Ankara'nın konumuyla açıklanabilir. Ankara özellikle Türkiye'de eğitim seviyesinde en yüksek konumdadır. Ayrıca Ankara 2014 yılı itibariyle ileri teknoloji, hizmet ve sanayi sektörlerinde en hızlı büyüyen il olmuştur. Metropol konumda olan Ankara; insan kaynakları, araştırma sistemleri, yatırım, nüfus, sağlık, kültür, ulaştırma, yenilik, bilimsel çıktılar, ekonomik çıktılar ve toplumsal refah değişkenlerinde öncü rol üstlenmektedir. Ayrıca bölgedeki diğer önemli il olan Konya da son yıllarda sanayi, eğitim, araştırma sistemleri, yatırım ve ekonomik çıktılarda önemli bir konuma sahiptir. Bu illerin sektör bazındaki ekonomik çeşitlilik bölgenin inovasyon sınıflamasında üst seviyede olmasına etki etmektedir.

\section{Sonuç}

$\mathrm{Bu}$ çalışmada, TR5 bölgesinin ekonomik açıdan inovasyon politikalarının gelişimi araştırılmaktadır. Bölgenin sürdürülebilir ekonomik büyüme gerçekleştirebilmesinin ön koşulu inovasyon politikalarını geliştirmesine bağlıdır. Özellikle inovasyon politikaları uygulayan temel kurumlar, finansmana yönelik kuruluşlar ve inovasyon üreten firmalar bölge ekonomisi için önem arz etmektedir. Bu doğrultuda inovasyon sistemi içerisindeki; insan kaynakları, araştırma sistemleri, yatırım-kredi-destekleri, nüfus, enerji, bilgi-iletişim teknolojileri, sağlık, ulaştırma, kültür, girişimcilik, ticari-mali aracılar, yenilikler, ekonomik ve bilimsel çıktılar ile toplumsal refah alt değişkenleri arasındaki performansın ölçülmesi gerek ülke gerekse de bölge açısından önem taşımaktadır. Bu önem alt değişkenlerin hem ekonomik büyümede hem de inovasyon sistemi içerisinde önemli bir rekabet faktörü olmasından kaynaklanmaktadır. Ulusal ve bölgesel rekabet üstünlüğüne etkileyen bu faktörler, teknolojinin hızla ilerlemesiyle birlikte iktisadi büyümeyi de olumlu yönde etkilemektedir. Bu çerçevede bölgesel inovasyon ve iktisadi büyümeye etki eden bu girdiçıktı modeli z skor normalizasyon yöntemiyle incelenmiştir. 
Bat1 Anadolu Bölgesi z-skor normalizasyon sıralamasında üst sınıfta yer almaktadır. Bölge inovasyon temel girdi değişkenlerinden özellikle altyapı-kültür değişkeninde birinci sırada yer alırken mümkün kılıcılar, girişimcilik-ticaret temel değişkenlerinde öne çıkmaktadır. Ayrıca girdi alt değişkenlerinde özellikle insan kaynakları, araştırma sistemleri, yatırım-kredi-destekleri, nüfus, bilgi-iletişim teknolojileri, sağlık, ulaştırma, kültür, girişimcilik ve ticari-mali aracı ile inovasyon çıktıları kapsamında da; yenilikler, ekonomik çıktılar, bilimsel çıktılar ve toplumsal refah alt değişkenlerinde $\mathrm{z}$ skor puanlaması bölge ekonomisinin gelişimine katkıda bulunmaktadır. Bu çerçevede bölge inovasyon sıralamasında üst sınıfta yer almaktadır. İnovasyon girdi-çıktı modeline göre Batı Anadolu Bölgesi’nin üst sınıfta yer almasına etki eden unsurlar; bölgede başkentin bulunması, başlıca büyük üniversitelerin bölge de yer alması, ekonomik sektörlerin gelişmiş olması şeklinde siralanabilir.

Özetle TR5 bölgesinin inovasyon sınıfı 15 alt değişken ve bu değişkenlere ait toplam 68 bileşenle belirlenmiştir. Bu çerçevede bölgesel inovasyona etki eden alt değişkenlerin geliştirilmesi bölge ekonomisinin daha dinamik olmasına katkıda bulunacaktır. Özellikle nitelikli emek geliştirilmesine yönelik uygulanacak olan gerek bölgesel gerekse de ulusal politikalar Türkiye'nin iktisadi büyümesini ve uluslararası rekabet gücünü sürekli kılarak artırabilir.

\section{Kaynakça}

Annoni P. \& Kozovska K. (2010), EU Regional Competitiveness Index, JRC Scientific and Technical Reports. (Reports No: EUR 24346 EN - 2010) Italy: European Commission.

Asheim T. B. \& Coenen L. (June2005), "Knowledge Bases and Regional Innovation Systems: Comparing Nordic Clusters”. Elsevier Resarch Policy 5(34),1173-1190.

Aydın, Cüneyt (2012). "MATLAB Ders

Notları",http://www.yildiz.edu.tr/ caydin/publications_dosyalar/Matlab_basic.pdf 
Cantner U.\& Meder A. (2009). "Regional Effects on Cooperative Innovation Activities and Related Variety of Regional Knowledge Bases", The Jena Economic Research Papers, 64, 1-27.

Cappelin R. \& Wink R. (2009). International Knowledge and Innovation Network (1th Edition). Cheltenham, UK: Edward Elgar Publishing Limited.

Cooke P. Roper S.\& Wylie P. (2001). Developing a Regional Innovation Strategy for Northern Ireland. Economic Council on Research Northern Ireland, 14 (2001), 1-74.

Doloreux, D. (2002). What We Should Know About Regional Systems of Innovation? Technology in Society, 24, 243-263.

Duman, E. (2017). Bölgesel İnovasyon ve İktisadi Büyüme: Düzey 1 Kapsamındaki Bölgelerin Normalizasyon Yöntemiyle Analizi. Selçuk Üniversitesi, İIBF İktisat ABD, Doktora Tezi, Konya.

Durgut, M. ve Akyoş M. (2001). "Bölgesel İnovasyon Sistemleri ve Teknoloji Öngörüsü”, http://www.inovasyon.org/pdf/mdbolginov.pdf,

Elçi, Ş. ve Karaata S. (2008). Bölgesel İnovasyon Merkezleri: Türkiye İçin Bir Model Önerisi, İstanbul: TÜSİAD.

Gregersen B. and Johnson B. (1996). Learning Economies, Innovation Systems and European Integration. Department of Business Studies Aalborg University, Denmark, 1-19.

Kocakoç, D. İ. (2015). Matlab ve Istatiksel Veri Analizi (3.Basım), Ankara: Nobel Akademik Yayıncılık.

Niosi J. (2008). “Technology, Development and Innovation Systems: An Introduction, Journal of Development Studies, 44(5), 613-621.

OECD. (2008). "Reviews of Regional Innovation”, North of England: OECD Publication Service. 
FSECON KARAÇOR, Z. ve DUMAN, E. (2017), "TR5 (Batı Anadolu) Bölgesinin İnovasyon Performans Kapasitesi Üzerine Bir Uygulama", Fiscaoeconomia, Vol.1(2), 73-87.

Sterberg, R. \& Müller C. (2005). "Entrepreneurship in Regional Innovation Systems", http://www.druid.dk/uploads/tx_picturedb/ds2005-1531.pdf.

Sternberg, R. (2007). Entrepreneurship, Proximity and Regional Innovation Systems. Tijdschriftvoor Economischeen Sociale Geografie, 98(5), 652-666.

TÜSİAD, (2008). “Türkiye'de Bölgesel Farklar ve Politikalar”, http://www.farklar.net/Genel/Turkiye-de_bolgesel_FaRkLaR.pdf. 